\title{
PHOSPHATIDILINOSITOL AND NESTING IMPOSSIBILITY: CASE REPORT
}

\author{
Carla Luchese de Almeida ${ }^{1, \star}$, Ana Paula Beckhauser ${ }^{1}$, Thelma Larocca Skare ${ }^{1}$
}

1.Hospital Evangélico Mackenzie de Curitiba, Paraná (PR), Brazil.

*Corresponding author: cah_luchese@hotmail.com

\section{BACKGROUND}

Antiphospholipid antibody syndrome (AAS) is an important issue to be taken into account in cases of pregnancy difficulties. Fetal-maternal crosstalk between the blastocyst and the endometrium is essential for successful implantation and pregnancy. The implantation process may be divided into three stages: apposition, adhesion and invasion. In endometriotic stromal cells, overactivation of the phosphatidylinositol 3-kinase (P13K)/AKT signaling pathway contributes to the reduced expression of the decidua-specific gene, IGFBP1, potentially important for implantation.

\section{CASE REPORT}

A 38-year-old nonsmoker Caucasian female was referred from her gynecologist after 40 unsuccessful attempts of pregnancy by implantation. She had no comorbidities or surgical/anatomical issues. Previous investigation discarded polycystic ovarian syndrome (POS), endometriosis, infections or hormone disorders (including thyroid). Husband's investigation including seminogram, anatomical and hormonal issues were normal. Her exams showed negative lupus anticoagulant (LAC) and anticardiolipins; however, a positive antiphosphatidylinositol (IgG =28; normal value = less than $10 \mathrm{U} / \mathrm{mL})$ test showed up. She had no clinical complaints and the physical exam was normal. She was treated with $0.5 \mathrm{mg} / \mathrm{kg} /$ day of prednisone introduced prior to a new implantation attempt plus enoxaparin with success. Anticoagulation was kept throughout pregnancy. Now, she has a two-year-old child.

\section{CONCLUSION}

The presence of the $\mathrm{P} 13 \mathrm{~K}$ antibody is one of the AAS that is not routinely requested. Nevertheless, the present case suggests that it may be the cause of nesting failure and should be considered in cases of pregnancy difficulties. 